\title{
The Effectivity of Phonics Method in Improving Reading Ability of 1st Grade Elementary School Students
}

\author{
W. Rahmah, L. N. Pandjaitan \\ Universitas Surabaya, Surabaya, Indonesia \\ lenapanjaitan66@gmail.com
}

\begin{abstract}
Reading is a basic skill that the students of the formal school must have. The Ministry of Education through BNSP has regulated the standard of reading ability for 1st-grade students of elementary school, that is able to read simple syllable, word, and sentence by using proper pronunciation and intonation. The aim of the research is to improve the reading ability of 1st-grade students in elementary school who is still less fluent to read. Phonics method is used as an intervention due to its systematic instructional step by practicing the phonological awareness, phonics and reading fluency (Hindle, 2007). The Informal Reading Assessment (IRA) developed by Ruscoe is used to measure the students' reading abilities. It is adjusted in Bahasa Indonesia by using adaptation process. The result of pretest and post-test shows the increasing of score and achievement category of reading skill. Further analyses reveal that improvement in reading ability happens in phonological awareness and phonics, but no significant improvement in reading fluency. In conclusion, it is required a lot of reading practice in order to make it more fluent.
\end{abstract}

Keywords—reading ability; phonic methods; elementary school;

\section{INTRODUCTION}

For a student, reading has several substantial effects which are increasing self-development in relation to developing of reasoning abilities and broad-mindedness, increasing the knowledge and vocabulary to train imagination and thinking abilities to fulfill the intellectual satisfaction, and obtaining the practical knowledge for everyday life (Stelee: 2017). Reading ability is the base to master various subjects, and if a child of elementary school age does not immediately have it, the child will experience many difficulties in studies on the next level [8].

A previous longitudinal study discovered that most of the elementary school students in the first grade who lacked reading abilities would experience failures in the fourth grade. If treatment is delayed up to nine years of age, then the child would experience low motivation to catch up to the gap on a higher grade (Campbell, Helf \& Cooke, 2008).

The researcher also conducted a preliminary survey by conducting an observation of students in two elementary schools, a state and a private school, in the first grade, both located in central town district of Sidoarjo. The result showed that there were 4 or 5 students from two observed schools with the total of 28 students who have difficulties in reading. Among these students, several of them had trouble in recognizing several letters, the tone of vocals and consonants, resulting in being late in the lessons compared to the other students with more developed reading abilities. Students experience obstacles in understanding the lesson especially with the reading materials, and the learning attitude is also hampered, as shown with reduced motivation and the students prefer to play than to follow the lessons in class.

The government of Indonesia already set the standards of reading competencies for students especially for those at the first grade of elementary school that is implemented in the reading aspects of Bahasa Indonesia subject (BNSP, 2006). The aspects are mentioned as follows: understanding short text with reading aloud, reading several simple sentences consisting of 3-5 words fluently with the correct pronunciation and intonation, and reading children's poem consisting of 2-4 lines with the correct pronunciation and intonation.

Difficulties in reading on the first grade were commonly caused by unfulfilled reading prerequisites. This was stated in a previous research (Capel-lini, Cesar, \& Germano, 2015) with the aim of identifying reading problems and the variables affecting it on the first-grade elementary school students. A total of 206 students, six to eleven years of age were evaluated using the seven aspects of cognitive-language skills, consisting of alphabetical knowledge, phonology awareness, memorizing ability, naming speed, visual attention, word and non-word reading, and image narration. It could be concluded from the results that there were three factors that had not been mastered by the students with initial reading difficulties on first grade, which were phonology awareness, visual attention, and lexical attention (word meaning) (Wagner \& Torgesen: 1987).

In increasing the reading abilities of the first-grade elementary school students, a reading remedial program is required, to help them practice the ability to process letters into words and associating written symbols into spoken language [9]. One of the required abilities, in order to become a fluent reader, is the ability to process sound (phonics) in the brain system (Shaywitz: 1996). Most problems with reading are not related to intelligence level but with processing 
disability. Teachers or tutors can help students with reading difficulties by teaching phonic processing first because this is an important ability to develop in order to establish the students to be expert readers (Gagen, 2007, cited in Lee, Gablen, \& Klassen, 2012).

This research focused on the improvement of reading ability on the first-grade elementary school students using the phonics reading method. The consideration in using this method was because it had a gradual learning process from the smallest unit, which was starting from learning the sound (phonics) as an introduction to letters, then combining letters into syllables, and lastly reading sentences. This method will be applied using learning aids that help students learn easier (Goodacre: 2012).

\section{METHOD}

This research used a pre-test and post-test experiment design (Campbell \& Stanley: 1966). Measurement of the reading abilities conducted before and after the treatment administration.

\section{A. Participants}

The participants of this research were students of elementary school, requires the improvement of reading ability based on the informal test regarding reading ability, recommended by teachers based on academic grades, agree to take the intervention conducted by filling the informed consent form administered to parents or based on the school permission.

\section{B. Research Procedure}

The research procedure was a set of a process from the assessment stage to the treatment stage. The assessment stage consists of a screening of students' academic data, obtaining the data of students' grade in Bahasa Indonesia subject, interview with teachers to obtain the data of students' reading ability, validation of IRA reading test in Bahasa Indonesia, measure participants' intelligence using CPM, and designing the intervention.

The process of treatment is as follows: preparing the equipment for intervention, implementing the intervention as scheduled, measuring the participants' reading ability after the treatment using IRA, and obtaining the data of students' reading ability.

The treatment consists of activities that increase three abilities. First is a phonological awareness that recognizes phonics on letters and identifies similar rhymes (Gillon: 2017). Secondly, recognize phonics through letters and words consist of stating letters and words, state and compare lowercase and capital letters, read simple words, reading words with many syllables, and read words with prefix and suffixes. The last is reading sentences and paragraphs fluency.

\section{RESULT AND DISCUSSION}

\section{A. Intervention Implementation}

The participants of this research were three students that fulfilled the criteria. Interventions were given in 36 sessions, each session was done in 45 minutes. The results were The category of reading abilities are very low $(X \leq 50)$, low $(51 \leq$ $X<92)$, average $(92 \leq X<134)$, good $(134 \leq X<175)$, and very good $(\geq 175)$.

TABLE I. PRE- AND POST-TEST RESULTS IN READING ABILITIES

\begin{tabular}{|c|c|c|}
\hline \multirow{2}{*}{ Participants } & \multicolumn{2}{|c|}{ Score of reading abilities test (total) } \\
\cline { 2 - 3 } & Pre & Post \\
\hline INS & 37 & 77 \\
\hline MDF & 45 & 81 \\
\hline MA & 28 & 127 \\
\hline
\end{tabular}

Based on pre- and post-test results, it could be concluded that there was an improvement of reading abilities on three participants, which were one level improvement from very low to low on subjects INS and MDF and two level improvement from very low to average on subject MA (Shek \& Sun: 2012).

The results of the statistical calculation using nonparametric shows that there were no significant differences in students' reading abilities before and after the intervention ( $p$ $=0.109>0.05)$.

Based on the description of results on each aspect, it was shown that there was an increase in phonological awareness on three subjects. Phonics pronunciation aspect also improves, with subjects INS and MDF showing one level improvement in score category (low to average) and subject MA showing four level improvement (very low to very good). On fluency aspect, all participants had not shown any improvement, all being in the very low category on both pre- and post-test.

The usage of the phonic method has been implemented as a program to prevent the difficulties in learning reading and used to reinforce students learning abilities in reading. According to some research, this method had higher effect if it is implemented in kindergarten and first-grade elementary school students (Snow et al., 1998; Campbell \& Cooke, 2008).

The components of the phonic method are known on both sound (phonics) and the name of letters. The phonologic awareness that consists of phonemic ability is the ability to listen and recognize the same sound (phonic) from a word (Adams: 1994). This requires the students to be able to memorize the word being spoken so that when the students are asked to re-speak it, they can do so. The phonic method imposes on the students to have visual attention to read words and non-words, with the final goal of forming students to be able to understand the sentences (Capellini et al. 2015). 


\section{CONCLUSION}

It is worth to point out that the intervention conducted in this research showed insignificant results. The continuous treatment using various visual and audio media in practicing the reading ability improves the participants' phonic awareness and letter-word pronunciation that will lead to the fluent reader. Nevertheless, the intense and the continuous treatment still needed until the level of a fluent reader is achieved. Therefore, the cooperation of the parents and the teachers play an important role in developing the students' ability in reading. The future research is suggested to be conducted related to this issue.

\section{REFERENCES}

[1] Campbell, M. L., Helf, S., \& Cooke, N. L. 2008. Effects of adding multisensory components to a supplemental reading program on the decoding skills of treatment resisters. Education \& Treatment of Children, 31(3), 267-295.

[2] Capellini, S. A, et al. 2014. Early Identification of Reading Problems: Preliminary Study with Students of 1st Grade. International Conference on New Horizons in Education, INTE (2014), 25-27 June 2014, Paris, France. 174: 1351-1355..

[3] Endress, S.A, Weston, H, \& Martella, N.E. 2007. Examining the Effect of Phono-Graphix on the Remediation of Reading Skills of Students with Disabilities: A Program Evaluation. Education \& Treatment of Children, 30(2), 1-20.

[4] Hindle, D. 2007. Teaching Reading in the Early Grade. Department of Education of South Africa. Cape Town: Formeset Digital
[5] Lee, G.-L.,\& Gable, R. 2012. "Effective Reading Remediation Instructional Strategies for Struggling Early Readers." Procedia - Social and Behavioral Sciences 46: 822-827.

[6] Nishanimut, S. P. \& Johnston, R.S. 2013. Effect of synthetic phonics instruction on literacy skills in an ESL setting. 27: 47-53.

[7] Ruscoe, K.A. 2003. Cool Tools Informal Reading Assessment. Florida: Department of Education.

[8] National Research Council. (2000). How people learn: Brain, mind, experience, and school: Expanded edition. National Academies Press.

[9] National Research Council. (1998). Preventing reading difficulties in young children. National Academies Press.

[10] Steele, T. (2007). Knowledge is power!: the rise and fall of European popular educational movements, 1848-1939. Peter Lang.

[11] Campbell, D. T., \& Stanley, J. C. (1966). Experimental and quasiexperimental designs for research. Handbook of research on teaching (NL Gage, Ed.), 171-246.

[12] Adams, M. J. (1994). Beginning to read: Thinking and learning about print. MIT press.

[13] Gillon, G. T. (2017). Phonological awareness: From research to practice. Guilford Publications.

[14] Wagner, R. K., \& Torgesen, J. K. (1987). The nature of phonological processing and its causal role in the acquisition of reading skills. Psychological bulletin, 101(2), 192.

[15] Shaywitz, S. E. (1996). A new model of this reading disorder emphasizes defects in the language-processing rather than the visual system. It explains why some very smart people have trouble learning to read. Scientific American.

[16] Shek, D. T., \& Sun, R. C. (2012). Promoting psychosocial competencies in university students: evaluation based on a one-group pre-test/post-test design.

[17] Goodacre, E. (2012). Children and Learning to Read (RLE Edu I). Routledge. 